\title{
Long-Term Effectiveness of the TIME Intervention to Improve Diabetes Outcomes in Low-Income Settings: a 2-Year Follow-Up
}

\author{
Elizabeth M. Vaughan, DO, $\mathrm{MPH}^{1,2}{ }^{\mathbb{D}}$, Evan Johnson, $P A^{3}$, Aanand D. Naik, $M D^{4,5}$, \\ Amber B. Amspoker, $P h D^{4,5}$, Ashok Balasubramanyam, $\mathrm{MD}^{6}$, \\ Salim S. Virani, MD, $P h D^{1,4,5}$, Christie M. Ballantyne, $M D^{7}$, Craig A. Johnston, $P h D^{7}$, and \\ John P. Foreyt, $P h D^{7}$
}

'Division of Atherosclerosis and Vascular Medicine, Department of Medicine, Baylor College of Medicine (Baylor), Houston, TX, USA; ${ }^{2}$ Division of General Internal Medicine, Baylor, Houston, TX, USA; ${ }^{3}$ School of Health Professions, Baylor, Houston, TX, USA; ${ }^{4}$ Houston Center for Innovations in Quality, Effectiveness, and Safety (IQuESt), Houston, TX, USA; ${ }^{5}$ Michael E. DeBakey VA Medical Center, Houston, TX, USA; ${ }^{6}$ Division of Diabetes, Endocrinology and Metabolism, Baylor, Houston, TX, USA; ${ }^{7}$ Department of Health and Human Performance, University of Houston, Houston, TX, USA.

BACKGROUND: We previously found that a 6-month multidimensional diabetes program, TIME (TelehealthSupported, Integrated Community Health Workers, Medication-Access) resulted in improved clinical outcomes.

OBJECTIVE: To follow TIME participant clinical outcomes for 24 months

PARTICIPANTS: Low-income Latino(a)s with type 2 diabetes

DESIGN AND INTERVENTION: We collected postintervention clinical data for five cohorts $(n=101$, mean $n=20$ (cohort) who participated in TIME programs from 2018 to 2020 in Houston, Texas.

MAIN MEASURES: We gathered HbAlc (primary outcome), weight, body mass index (BMI), and blood pressure data at baseline, 6 months (intervention end), and semiannually thereafter until 24 months after baseline to assess sustainability. We also evaluated participant loss to follow-up until 24 months.

KEY RESULTS: Participants decreased HbAlc levels during the intervention $(p<0.0001)$ and maintained these improvements at each timepoint from baseline to 24 months ( $p$ range: $<0.0001$ to 0.015 ). Participants reduced blood pressure levels during TIME and maintained these changes at each timepoint from baseline until 18 months (systolic $p$ range $<0.0001$ to 0.0005 , diastolic $p$ range: $<0.0001$ to 0.008 ) but not at 24 months (systolic: $p=0.065$; diastolic: $p=0.85$ ). There were no significant weight changes during TIME or post-intervention: weight ( $p$ range $=0.07$ to 0.77 ), BMI ( $p$ range $=0.11$ to 0.71 ). Attrition rates (loss to follow-up during the post-intervention period) were $5.9 \%$ (6 months), $24.8 \%$ (12 months), 35.6\% (18 months), and $41.8 \%$ (24 months).

CONCLUSIONS: It is possible for vulnerable populations to maintain long-term glycemic and blood pressure improvements using a multiple dimensional intervention. Attrition rates rose over time but show promise given the

Received June 8, 2021

Accepted December 16, 2021

Published online February 7, 2022 majority of post-intervention timepoints occurred during the COVID-19 pandemic when low-income populations were most susceptible to suboptimal healthcare access. Future studies are needed to evaluate longitudinal outcomes of diabetes interventions conducted by local clinics rather than research teams.

KEY WORDS: diabetes; telehealth or telemedicine; community health worker (CHW); group visits or shared medical appointments; access to care; disparities; low-income.

J Gen Intern Med 37(12):3062-9

DOI: $10.1007 / \mathrm{s} 11606-021-07363-7$

(C) The Author(s) under exclusive licence to Society of General Internal Medicine 2022

\section{INTRODUCTION}

There are 34.2 million people with diabetes in the USA, constituting $13.0 \%$ of the adult population and including an estimated 7.3 million individuals who are unaware of their disease. ${ }^{1}$ Individuals with diabetes incur more than twice the medical expenditures compared to those without, including $\$ 90$ billion for lost productivity. Diabetes care costs $\$ 327$ billion annually, consuming $25 \%$ of US healthcare dollars. ${ }^{2}$

Individuals with diabetes from low socioeconomic status face numerous barriers to care. These include medication access, transportation, language, healthy food availability, health literacy, and insurance. ${ }^{3,4}$ Latino(a)s are twice as likely to develop diabetes than non-Hispanic whites and suffer from more complications, hyperglycemia, and poor quality of life. ${ }^{1,5}$ Numerous targeted diabetes intervention studies have demonstrated improved outcomes among low-income minorities. ${ }^{6-8}$ However, a key gap is follow-up data to evaluate longterm maintenance of the outcomes achieved during active interventions.

We previously evaluated the effects of combining four individually validated strategies (telehealth, community health workers (CHWs), medication access, group visit education) in 
the TIME programs conducted at community clinics serving low-income Latino(a)s. ${ }^{9-11}$ TIME included a 6-month intervention followed by 6 months of CHW follow-up to bridge care. It was the first study to our knowledge to integrate CHWs into group visit leadership teams as well as utilize telehealth to provide ongoing CHW support. During the intervention, participants significantly improved diabetes outcomes compared to the control arm including lower HbA1c $(-1.43 \%$ vs. $-0.45 \%, p=0.002)$, improved blood pressure levels (systolic: $-6.89 \mathrm{mmHg}$ vs. $0.003 \mathrm{mmHg}, p$ $=0.023$; diastolic: $-3.36 \mathrm{mmHg}$ vs. $0.2 \mathrm{mmHg}, p=0.046$ ), and greater American Diabetes Association guideline adherence $(p<0.001)$ from baseline to 6 months, respectively, but did not result in significant body mass index (BMI) or weight reductions. The program also showed the value of CHWs in identifying barriers to care that may have otherwise been unrecognized. ${ }^{9-11}$ The clinical outcomes achieved during TIME are important, but it is not known if these clinical outcomes would be sustainable over time or worsen as would be expected without an intervention. ${ }^{12-15}$

In this study, we evaluated post-intervention data of TIME participants. Specifically, we recorded semiannual HbA1c (primary outcome), blood pressure, weight, and BMI data from baseline to 24 months to assess sustainability. We hypothesized that the significant clinical improvements achieved during the TIME programs, in particular HbAlc and blood pressure reduction, would be sustained during the postintervention period.

\section{METHODS}

\section{Study Design and Setting}

This was an observational follow-up study of five cohorts who participated in the TIME program from January 2018 to February 2020 in Houston, Texas. The five cohorts included the two original intervention arms $(n=22 \text {, each })^{9-11}$ and three cohorts $(n=15, n=22, n=20)$ in subsequent programs. The methodology of the TIME program has been described previously $^{9-11}$; sites were nonprofit, $501 \mathrm{c}(3)$ community clinics that served only uninsured and low-income individuals earning $\leq 150 \%$ of the federal poverty level. Individuals who were insured or earned greater than the allotted income were not eligible for clinic services. Study inclusion criteria were adults $\geq 18$ years, Latino(a)s, type 2 diabetes ( $\mathrm{HbAlc} \geq 6.5 \%$ ), and Spanish-speaking. Individuals were excluded if they did not attend at least one group visit $(n=0)$; were pregnant $(n=1)$; had severe cognitive impairment $(n=0)$; required frequent provider encounters, e.g., for labile glucose levels $(n=1)$; or had a treatment or condition that could alter reliable $\mathrm{HbA} 1 \mathrm{c}$ measurements $(n=2) .{ }^{16}$ Recruitment processes included contacting potential participants identified by a clinic database or provider referrals, inviting interested individuals to an orientation for written consent, and baseline data collection, i.e.,
HbA1c. This study was approved by the Baylor College of Medicine Institutional Review Board.

Intervention: Months 1-6. The TIME intervention is described elsewhere. ${ }^{9-11}$ It consisted of 3-h, CHW-led monthly group visits for 6 months. Group visits included large-group diabetes education, small-group breakout sessions that addressed barriers to care, healthy meal education with food examples, and a 1:1 medical encounter with a provider. Telehealth (video conferencing, mobile health (mHealth) phone/text) was utilized to enhance CHWparticipant and CHW-provider communication. ${ }^{17,18}$ Providers met with CHWs weekly via video conferencing for training and support; CHWs contacted participants via mHealth weekly to reiterate educational topics from group visits, obtain glucose values, ensure medication adherence, and answer questions. ${ }^{9-11}$

Post-Intervention: Months 7-24. Starting in month seven, participants returned to usual care in the clinic with their primary care providers in lieu of receiving care from the study physicians. During months $7-12$, the CHWs continued to contact participants via mHealth to bridge care to the clinic. During months 13-24, participants continued to receive usual care in the clinic but did not receive $\mathrm{CHW}$ communication.

\section{Measures}

Clinical Outcomes. TIME baseline occurred at month one, and TIME ended at month six. Post-intervention timepoints were at 12, 18, and 24 months after baseline. We assessed clinical sustainability using electronic medical records (EMRs) (EPIC, Athena Health) and collecting quarterly HbAlc (primary outcome), weight, BMI, and systolic and diastolic blood pressure values from baseline to 24 months. Data at each timepoint was the mean \pm 3 months, e.g., the 12 month value was the average of 9,12 , and 15 months. We chose this method to more accurately capture trends due to the high levels of between-visit clinical variability in low-income areas. ${ }^{12,19}$

Medication Access. Medication access and adherence to treatment are often limited by cost, education, and access to care in low-income settings, resulting in glucose variability. ${ }^{19}$ Therefore, we recorded whether participants received $\geq 1$ high-cost medication (> \$10/month) during and after TIME. We also documented if individuals received insulin during the intervention and post-intervention. ${ }^{20}$

CHW-Participant mHealth Outcomes. We evaluated the frequency of successful CHW-participant mHealth contact, defined as communicating with participants via phone or text message. 
Attrition Outcomes. We also assessed participant loss to follow-up (attrition), defined as not receiving treatment by a provider for diabetes, i.e., primary care appointment at each timepoint. We excluded visits that were not diabetes-related or not with a primary care provider (e.g., mammogram or nutritionist appointments) in order to capture the ability to collect long-term diabetes outcomes in this population.

\section{Statistical Analysis}

We examined change over time in each clinical outcome: HbAlc, weight, BMI, and blood pressure (systolic and diastolic). For each outcome, we constructed two growth curve models. We constructed a linear multilevel growth curve model with the outcome as the dependent variable, and the baseline variable of the outcome and time as independent variables. Time was coded as such: baseline $=0,6$ months $=$ 1,12 months $=2,18$ months $=3$, and 24 months $=4$. Time was included as both a fixed and a random effect, and an unstructured covariance matrix was specified. For each outcome, we conducted a quadratic multilevel growth curve model. The only difference was the addition of a time $\times$ time interaction as a predictor. For HbA1c, we examined whether change in values over time varied as a function of whether it was controlled at 6 months $(<7 \%$ for $<65$ years, $<$ $7.5 \%$ for $>65$ years). We repeated the linear model adding the time $\times$ control interaction term and repeated the quadratic model, adding the time $\times$ time $\times$ control interaction term.

We then used repeated-measurest tests to examine improvement in each of the five outcomes during the active period (i.e., baseline to 6 months). We repeated these tests to examine maintenance of effects from baseline to each follow-up period. For each outcome, three additional repeated-measurest tests were conducted to examine maintenance from baseline to 12 , 18, and 24 months. If HbA1c levels were not available but glucose levels were recorded (1\% of timepoints), we converted these values to HbAlc using the equation $(46.7+$ (mean glucose))/26.7. ${ }^{21,22}$ To account for potential variations between glucose and $\mathrm{HbA} 1 \mathrm{c}$ data, we recorded the mean glucose values if more than one was available and examined whether any proxy glucose values were outliers (i.e., exceeded two standard deviations beyond individuals' mean HbAlc data). Missing HbAlc data ( $n=101$ except 24 months $(n=$ 79)) were baseline (0\%), 6 months (3.96\%), 12 months (25.74\%), 18 months (36.64\%), and 24 months (45.57\%). A total of $21.33 \%(103 / 483)$ of all data points were missing.

We conducted a series of independent-samplest tests to determine if mean age or baseline clinical scores differed between those missing data and those with complete data. All models were repeated using intent-to-treat(ITT) methods and employed the multiple imputation procedures PROC MI and MI ANALYZE in SAS Version 9.4 (SAS Institute, Cary, NC) to handle missing data. Analyses were reported using paired $t$ test with multiple imputations if missing data were present. For completeness, analyses were also conducted using paired $t$ test without multiple imputations. Binomial data (CHW contact, participant attrition, medication data) were recorded as yes/no and proportions were evaluated.

\section{RESULTS}

Study data reflects the combined fived cohorts' outcomes. Table 1 illustrates baseline characteristics of individuals $(n=$ 101, mean 20.2/cohort) who participated in TIME programs. Mean participant age was 54.8 years, more females $(67.3 \%)$ participated, and nearly half $(45.5 \%)$ did not have a legal status. Most individuals worked in domestic (44.6\%) or manual labor $(22.8 \%)$ employments and received oral hypoglycemics alone $(60.4 \%)$ or oral(s) with injectable(s) $(36.6 \%)$. Individuals averaged 12.3 years since diabetes diagnosis. Mean baseline clinical levels were blood pressure 132.7/76.4 mmHg, HbAlc $8.56 \%$, BMI $33.4 \mathrm{~kg} / \mathrm{m}^{2}$, total cholesterol $180.4 \mathrm{mg} / \mathrm{dL}$, triglycerides $180.9 \mathrm{mg} / \mathrm{dL}$, HDL-C $48.9 \mathrm{mg} /$ $\mathrm{dL}$, and LDL-C $99.3 \mathrm{mg} / \mathrm{dL}$. Those missing any data did not differ from those with complete data on age or any baseline clinical scores (all $p>0.05$ ).

\section{Medication Access and Attrition Outcomes}

Clinic and medication eligibility concerns were the most common participant issue during the post-intervention period. The

Table 1 Baseline Characteristics of Low-Income Latino(a)s with Type 2 Diabetes Who Participated in TIME Programs $(n=101)$

\begin{tabular}{ll}
\hline \hline Variable & Mean \pm SD orn(\%) \\
\hline Age (years) & $54.8 \pm 8.4$ \\
Sex $(n)$ & $33(32.7)$ \\
Male & $68(67.3)$ \\
Female & \\
Legal status $(n)$ & $56(55.5)$ \\
Documented & \\
Employment $(n)$ & $45(44.6)$ \\
Domestic & $23(22.8)$ \\
Manual labor & $12(11.9)$ \\
Food service & $14(13.9)$ \\
Unemployed & $7(6.8)$ \\
Other/unknown & \\
Diabetes therapy $(n)$ & $3(3.0)$ \\
Lifestyle only & $61(60.4)$ \\
Oral hypoglycemic(s) only & $37(36.6)$ \\
Oral hypoglycemic(s) with injectable(s) & $0(0.0)$ \\
Injectable(s) only & $12.3 \pm 8.7$ \\
Time since diabetes diagnosis (years) & $8.56 \pm 2.1$ \\
HbA1c (\%) & $183.12(46.43)$ \\
Weight (lb) & $33.4 \pm 21.1$ \\
Body mass index (kg/m $\left.{ }^{2}\right)$ & \\
Blood pressure (mmHg) & $132.7 \pm 15.1$ \\
Systolic & $76.4 \pm 9.8$ \\
Diastolic & \\
Cholesterol (mg/dL) & $180.4 \pm 43.7$ \\
Total & $180.9 \pm 89.5$ \\
Triglycerides & $48.9 \pm 14.5$ \\
HDL-C & $99.3 \pm 37.4$ \\
LDL-C & \\
\hline
\end{tabular}

TIME Telehealth-Supported, Integrated Community Health Workers, Medication-Access 
proportion of individuals receiving high-cost medications and insulin decreased during TIME but increased in the postintervention period when they returned to clinic. A total of $59.4 \%$ received high-cost medications at baseline. This proportion decreased to $53.5 \%$ during the intervention but increased to $62.8 \%$ during the post-intervention period. Similarly, $33.7 \%, 26.7 \%$, and $31.4 \%$ received insulin at baseline, 6 months, and post-intervention, respectively (Fig. 1). The differences in high-cost medications and insulin use at baseline, 6 months, and during the postintervention period were not significant: high-cost medications (baseline to 6 months: $p=0.397,6$ to 24 months: $p$ $=0.113$ ), insulin (baseline to 6 months: $p=0.307,6$ to 24 months: $p=0.513$ ).

\section{CHW-Participant mHealth Outcomes}

Participant group visit attendance averaged 4.2/6 (72.0\%) sessions, and most $(85.2 \%)$ were present for three or more classes. CHWs successfully contacted participants via mHealth an average of 15.2/20 (76.0\%) of attempts during the intervention (months 1-6) and an average of 6.1/12 $(50.1 \%)$ of attempts in months $7-12$. Common concerns participants relayed to CHWs included medication refills, eligibility, and other access to care issues.

\section{Clinical Outcomes}

All proxy glucose values $(n=5)$ were within two standard deviations of individuals' mean $\mathrm{HbAlc}$ data and were, therefore, retained for analyses. We conducted linear and quadratic growth curve models for each outcome at baseline and at 6, 12, 18, and 24 months (Table 2). Controlling for respective baseline scores, growth curve models using multiple imputations revealed a significant decrease with some loss of gains over time for $\mathrm{HbA1c}$ (linear: $p=0.07$, quadratic: $<0.0001$ ), systolic blood pressure (linear: $p=0.001$, quadratic: 0.0007), and diastolic blood pressure (linear: $p=0.12$, quadratic: 0.003 ) but not weight (linear: $p=0.42$, quadratic: 0.30 ) or BMI (linear: $p=0.43$, quadratic: $p=0.22$ ). For every 6 -month



Figure 1 Proportion of low-income Latino(a)s with type 2 diabetes who participated in diabetes programs $(n=101)$ who received highcost medications and insulin during and post-intervention (*intervention end). period, systolic blood pressure decreased, on average, by 1.74 points. Quadratic multilevel growth curve models using multiple imputations revealed a significant initial improvement that lessened over time for HbA1c $(p=0.001)$ and diastolic $(p=0.02)$ and systolic blood $(p=0.03)$ pressure but not for weight $(p=0.12)$ and BMI $(p=0.12)$. Furthermore, HbAlc change over time did not vary as a function of whether it was controlled or uncontrolled at 6 months (linear time $x$ control effect: $b(\mathrm{SE})=-0.02(0.08), t(272)=-0.24, p=0.81$, quadratic time $\times$ time $\times$ control effect: $b(\mathrm{se})=0.02(0.05)$, $t(399)=0.42, p=0.67)$.

Table 3 and Figure 2 show HbA1c, weight, BMI, and blood pressure values at baseline to $6,12,18$, and 24 months. HbA1c levels decreased significantly during the intervention (baseline to 6 months, $p<0.0001$ ) and were sustained from baseline to each timepoint through 24 months (range: $p<0.0001$ to $p=$ 0.015 ). Blood pressure levels decreased significantly during the intervention (systolic: $p<0.0001$, diastolic: $p=0.004$ ), and these improvements were sustained at each timepoint through 18 months but not at 24 months (12 to 18 -month systolic range: $p<0.0001$ to $p=0.0005,24$ months $p=$ $0.065 ; 12$ to 18 -month diastolic range: $p<0.0001$ to $p=$ $0.008 ; 24$ months: $p=0.85$ ). There were no significant weight or BMI changes during intervention or post-intervention (weight range: $p=0.07-0.77$, BMI range: $p=0.11-0.71$ ). Comparisons of analyses with and without multiple imputations revealed that significance did not change with the exception of baseline to 18-month diastolic blood pressure (multiple imputations with: $p=0.008$ and without: $p=0.07$ ).

Figure 2 illustrates these clinical trends in addition to attrition rates. Attrition levels were $<50 \%$ at all timepoints: $5.9 \%$ (6 months), $24.7 \%$ (12 months), 35.6\% (18 months), and $41.8 \%$ (24 months). Attrition was due to loss of eligibility to attend the clinic (22.8\% obtained insurance, $15.8 \%$ had insufficient paperwork), relocation or deceased $(7.0 \%)$, or unknown (54.4\%). However, $78.5 \%$ of the scheduled timepoints occurred during the state-widestay-at-home orders or reduce clinic access due to COVID-19.

\section{DISCUSSION}

This post-intervention analysis evaluated follow-up data from low-income Latino(a)s who participated in the 6-month TIME program. We found $\mathrm{HbAlc}$ and blood pressure improvements achieved during the TIME intervention were statistically significantly sustained through 18 and 24 months, respectively. This encourages a model in which a focused, TIME-like multidimensional intervention by an expert group may be sufficient to provide longer-term benefits and could be implemented in routine clinical settings.

Studies have shown that the natural progression of $\mathrm{HbA1c}$ and blood pressure is to increase over time. ${ }^{12-15}$ Investigators have also demonstrated that if participants remain in an intervention long term, clinical markers can remain stable. ${ }^{23}$ For 
Table 2 Results of Linear and Quadratic Growth Curve Models for Each Clinical Outcome $(n=101)$

\begin{tabular}{|c|c|c|c|c|c|c|c|c|}
\hline \multirow[t]{2}{*}{ Variable } & \multicolumn{4}{|l|}{ Linear model } & \multicolumn{4}{|c|}{ Quadratic model } \\
\hline & $b$ (SE) & $t$ value & df & $p$ value & $b$ (SE) & $t$ value & df & $p$ value \\
\hline \multicolumn{9}{|l|}{$\mathrm{HbA1c}(\%)$} \\
\hline Effect of time & $-0.07(0.04)$ & -1.84 & 49.12 & 0.07 & $-0.49(0.12)$ & -4.19 & 75.85 & $<0.0001$ \\
\hline Quadratic effect of time & N/A & N/A & N/A & N/A & $0.10(0.03)$ & 3.45 & 61.73 & 0.001 \\
\hline \multicolumn{9}{|l|}{ Weight (lb) } \\
\hline Effect of time & $-0.29(0.35)$ & -0.82 & 52.62 & 0.42 & $1.05(0.81)$ & 1.29 & 65.48 & 0.30 \\
\hline Quadratic effect of time & N/A & N/A & N/A & N/A & $-0.34(0.21)$ & -1.58 & 45.47 & 0.12 \\
\hline \multicolumn{9}{|l|}{ Body mass index $\left(\mathrm{kg} / \mathrm{m}^{2}\right)$} \\
\hline Effect of time & $-0.05(0.06)$ & -0.80 & 56.06 & 0.43 & $0.19(0.15)$ & 1.24 & 62.58 & 0.22 \\
\hline Quadratic effect of time & N/A & N/A & $\mathrm{N} / \mathrm{A}$ & N/A & $-0.06(0.04)$ & -1.56 & 48.23 & 0.12 \\
\hline \multicolumn{9}{|c|}{ Blood pressure (systolic) (mmHg) } \\
\hline Effect of time & $-1.74(0.51)$ & -3.42 & 40.59 & 0.001 & $-4.98(1.39)$ & -3.58 & 64.36 & 0.0007 \\
\hline Quadratic effect of time & N/A & N/A & N/A & $\mathrm{N} / \mathrm{A}$ & $0.81(0.36)$ & 2.29 & 52.68 & 0.03 \\
\hline \multicolumn{9}{|c|}{ Blood pressure (diastolic) ( $\mathrm{mmHg}$ ) } \\
\hline Effect of time & $-0.46(0.29)$ & -1.59 & 44.37 & 0.12 & $-2.56(0.83)$ & -3.08 & 65.06 & 0.003 \\
\hline Quadratic effect of time & $\mathrm{N} / \mathrm{A}$ & N/A & N/A & N/A & $0.53(0.21)$ & 2.45 & 52.28 & 0.02 \\
\hline
\end{tabular}

Analyses were intent to treat and used multiple imputation methods; models included the respective outcome variable at baseline as a covariate

example, a 5-year study of 120 individuals randomized to group (intervention) or individual (control) diabetes care revealed that $\mathrm{HbA} 1 \mathrm{c}$ levels remained stable for intervention but not control participants (intervention: $0.1 \%$; control: $1.7 \%) .^{23}$ However, long-term interventions may not be feasible in low-resource areas. Other investigators demonstrated that the prolonged COVID-19 lockdowns alone played a major role in worsening glucose control. ${ }^{24}$ Our study showed that participants may not need to remain in an active intervention trial for a long period of time, even during COVID-19, to maintain significant clinical improvements in $\mathrm{HbAlc}$ and blood pressure.

Post-intervention information is critical to determine efficacy and sustainability in addition to maximizing resource utilization. However, there is a paucity of post-intervention data involving CHWs in diabetes initiatives. A study of Mexican

Table 3 Clinical Outcomes of Low-Income Latino(a)s with Type 2 Diabetes Who Participated in TIME $(n=101)$

\begin{tabular}{|c|c|c|c|c|c|}
\hline \multirow[b]{2}{*}{ Variable } & \multirow[b]{2}{*}{ Mean (SD) } & \multicolumn{4}{|c|}{$\begin{array}{l}\text { Results of paired } t \text { test with multiple imputation representing change } \\
\text { from baseline to each follow-up assessment }\end{array}$} \\
\hline & & $b$ (SE) & $t$ value & df & $p$ value \\
\hline \multicolumn{6}{|l|}{ HbAlc $(\%)$} \\
\hline Baseline $(n=101)$ & $8.56(2.09)$ & & & & \\
\hline 6 months (intervention end) $(n=97)$ & $7.56(1.65)$ & $1.00(0.14)$ & 6.91 & 54363.0 & $<0.0001$ \\
\hline 12 months $(n=75)$ & $7.93(1.76)$ & $0.64(0.15)$ & 4.17 & 660.2 & $<0.0001$ \\
\hline 18 months $(n=64)$ & $8.00(1.77)$ & $0.43(0.17)$ & 2.54 & 133.2 & 0.012 \\
\hline 24 months $(n=43)$ & $8.10(1.49)$ & $0.46(0.18)$ & 2.50 & 84.1 & 0.015 \\
\hline \multicolumn{6}{|l|}{ Weight (lb) } \\
\hline Baseline $(n=101)$ & $183.12(46.43)$ & & & & \\
\hline 6 months (intervention end) $(n=90)$ & $182.93(46.80)$ & $0.19(0.67)$ & 0.29 & 100.0 & 0.77 \\
\hline 12 months $(n=69)$ & $187.38(45.48)$ & $-1.06(0.98)$ & -1.08 & 264.0 & 0.28 \\
\hline 18 months $(n=61)$ & $187.60(39.55)$ & $1.15(1.54)$ & -0.74 & 240.6 & 0.46 \\
\hline 24 months $(n=35)$ & $187.71(54.23)$ & $3.76(1.93)$ & 1.83 & 68.6 & 0.07 \\
\hline \multicolumn{6}{|l|}{ Body mass index $\left(\mathrm{kg} / \mathrm{m}^{2}\right)$} \\
\hline Baseline $(n=101)$ & $33.4(7.13)$ & & & & \\
\hline 6 months (intervention end) $(n=90)$ & $33.4(7.13)$ & $0.04(1.25)$ & 0.37 & 100.0 & 0.71 \\
\hline 12 months $(n=67)$ & $34.0(6.71)$ & $-0.22(0.20)$ & -1.09 & 158.86 & 0.28 \\
\hline 18 months $(n=61)$ & $34.2(5.79)$ & $-0.23(0.28)$ & -0.82 & 255.78 & 0.41 \\
\hline Baseline to 24 months $(n=35)$ & $34.4(7.06)$ & $0.54(0.34)$ & 1.61 & 79.56 & 0.11 \\
\hline \multicolumn{6}{|l|}{ Blood pressure (systolic) (mmHg) } \\
\hline Baseline $(n=101)$ & $132.73(15.13)$ & & & & \\
\hline 6 months (intervention end) $(n=87)$ & $125.88(14.20)$ & $6.85(1.59)$ & 4.31 & 100.0 & $<0.0001$ \\
\hline 12 months $(n=70)$ & $123.79(12.38)$ & $8.43(1.54)$ & 5.46 & 1434.5 & $<0.0001$ \\
\hline 18 months $(n=55)$ & $125.19(15.20)$ & $6.76(1.92)$ & 3.53 & 180.7 & 0.0005 \\
\hline 24 months $(n=26)$ & $126.42(16.21)$ & $6.13(3.27)$ & 1.88 & 69.8 & 0.065 \\
\hline \multicolumn{6}{|l|}{ Blood pressure (diastolic) (mmHg) } \\
\hline Baseline $(n=101)$ & $76.41(9.83)$ & & & & \\
\hline 6 months (intervention end) $(n=87)$ & $73.61(8.26)$ & $2.79(0.94)$ & 2.97 & 100.0 & 0.004 \\
\hline 12 months $(n=70)$ & $72.30(8.19)$ & $3.93(1.02)$ & 3.87 & 1435.9 & $<0.0001$ \\
\hline 18 months $(n=55)$ & $73.00(7.60)$ & $3.19(1.19)$ & 2.67 & 302.7 & 0.008 \\
\hline 24 months $(n=26)$ & $76.83(8.62)$ & $-0.34(1.77)$ & -0.19 & 69.9 & 0.85 \\
\hline
\end{tabular}

TIME Telehealth-Supported, Integrated Community Health Workers, Medication-Access

*For completeness, analyses were also conducted using paired t test without multiple imputations. These analyses were compared, and significance did not change with the exception of baseline to 18-month diastolic blood pressure: multiple imputations with: $p=0.008$, without: $p=0.07$ 


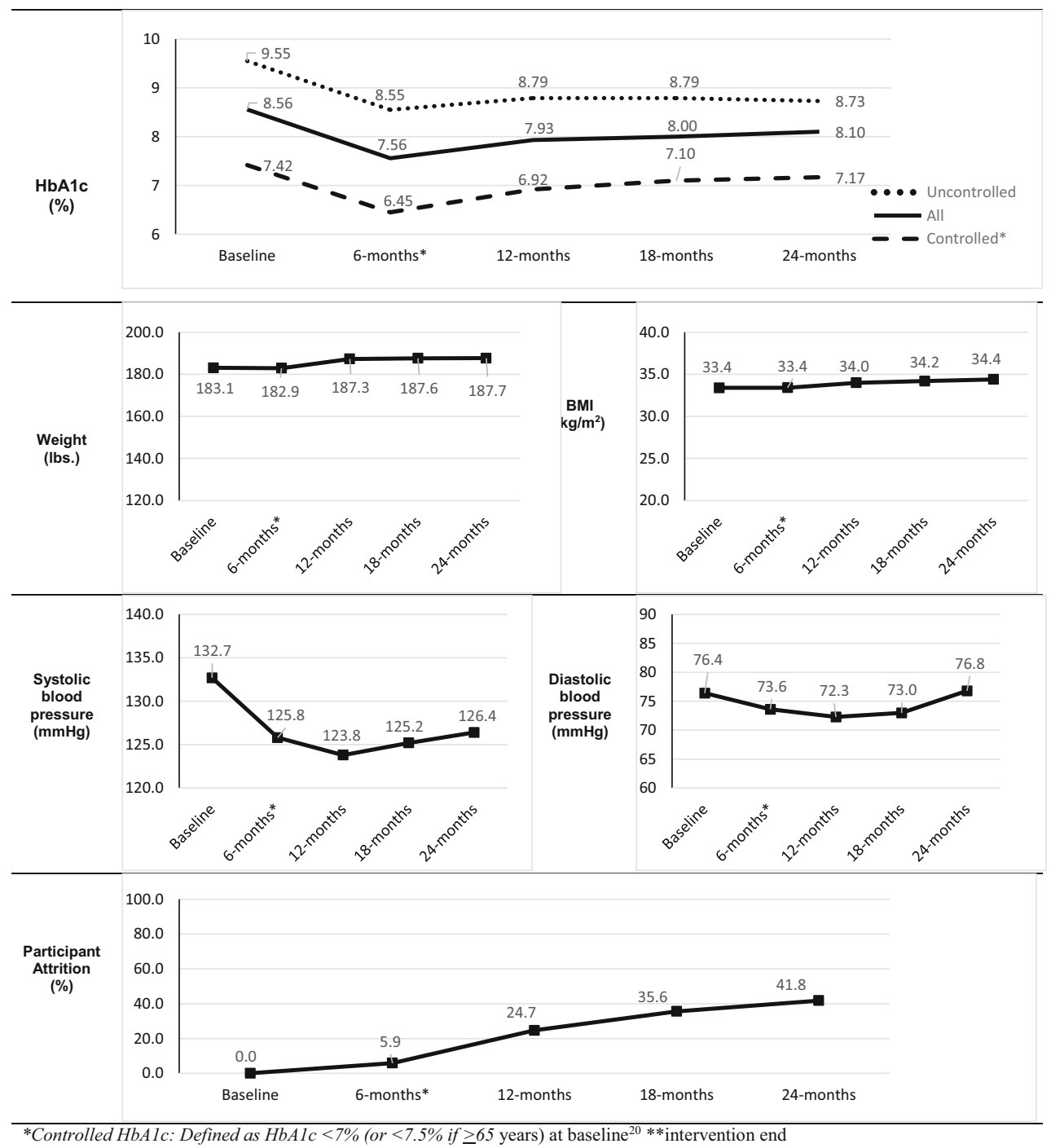

Figure 2 Clinical and attrition trends for individuals $(n=101)$ who participated in diabetes programs from baseline to 24 months. *Controlled HbA1c: defined as HbA1c $<7 \%$ (or $<7.5 \%$ if $\geq 65$ years) at baseline. ${ }^{20} * *$ Intervention end.

Americans participating in $36 \mathrm{CHW}$-led home visits delivered for 2 years resulted in $\mathrm{HbAlc}$ reductions of $0.69 \%$, but postintervention data are not included. ${ }^{25}$ A 12-month CHW intervention with follow-up data revealed that HbAlc improvements were sustainable ( $p=0.002)$, but post-intervention data duration was only 6 months. ${ }^{26}$ Long-term data trends provided by our study were of particular importance since the greatest clinical regression and increases in attrition levels occurred immediately after participants completed the intervention.

There are several possibilities for the clinical regression and increased attrition rates during months 7-12. The majority (78.5\%) of data timepoints occurred during the COVID-19 pandemic. This affected clinic eligibility, medication availability, and other aspects of access to care including obtaining routine laboratory values, e.g., HbA1c. Additionally, the clinic ensured that all participants maintained their clinic eligibility in order to complete TIME during the active intervention period, including those who may have lost access otherwise, e.g., incomplete paperwork or obtaining insurance. This likely contributed to the initial increased attrition after the intervention. Further, some clinic providers changed participant medications to high-cost agents or insulin. Recent Medicaid expansions make it easier to obtain high-cost medications, but many in our population would not meet the requirements, e.g., inability to provide citizenship or residency status. ${ }^{27}$ In addition, barriers to insulin in underserved populations including lower education attainment, food insecurity, and access to care significantly increase the likelihood of medication nonadherence, hypoglycemic episodes, and poorly controlled diabetes. $^{28-30}$ On the other hand, blood pressure medications are typically generic, reducing access barriers. This may provide rationale for more stable blood pressure levels postintervention.

Though not entirely clear, there are few possibilities why BMI and weight trends increased during the post-intervention period (months 7-12). The majority of study timepoints occurred during COVID-19, which negatively impacted weight. Investigators found that nearly half of individuals gained 
weight, reporting poor dietary habits and high stress levels; average BMI and weight levels increased $0.54 \mathrm{~kg} / \mathrm{m}^{2}$ and 0.62 $\mathrm{kg}$, respectively, during the pandemic. ${ }^{24,31}$ In our population, most employments were active, e.g., manual labor, which decreased or was omitted during COVID-19, further risking inactivity. Additionally, TIME focuses on prescribing hypoglycemics that are available to low-income populations. Two of the three available (pioglitazone, sulfonylureas) are associated with weight gain. ${ }^{20}$

It is likely that the effects of CHW involvement during the post-intervention period were likely not immediate. For example, the timeframe for participants to receive post-intervention appointments, and realize and communicate barriers to CHWs, and for CHWs to provide assistance often lasted several months. It is probable, however, that CHW involvement during months 7-12 enhanced the sustainability of clinical outcomes. Future studies are needed to evaluate the efficacy of longitudinal CHW-participant mHealth communication in improving engagement in healthcare systems.

This study had several strengths. One strength of this study is that we obtained long-term data of clinical trends in an underserved population. These trends included the transition to "real-world" care and other relevant parameters of diabetes management beyond $\mathrm{HbA} 1 \mathrm{c}$ levels, i.e., blood pressure, weight, BMI, attrition rates, and medication access. To our knowledge, the TIME program is the first to involve CHWs as group visit leaders as well as key members in the research team, providing valuable input in study recruitment and implementation processes.

The study also had limitations. Though attrition was expected in the post-intervention period, it enhanced difficulty of collecting data, limited power, and potentially resulted in selection bias. ${ }^{32}$ In addition, COVID-19 imposed restrictions, likely decreasing access to care and increasing missing data including HbAlc levels, resulting in using glucose values for some points. However, more than half of the participants remained active in the clinic for diabetes care at month 24 during the pandemic. Additionally, the data are retrospective and observational without a control arm. Future, prospective randomized studies managed by routine clinic personnel are warranted.

\section{CONCLUSIONS}

This study revealed that a multidimensional diabetes program may be a valuable modality for vulnerable populations to sustain long-term clinical outcomes. Future studies are warranted to assess long-term outcomes of diabetes interventions conducted by local clinics rather than research teams.

\section{Acknowledgements:}

The authors wish to thank the study participants, CHWs, and clinical sites for their contributions to the study. The authors are grateful for the overwhelming and endless support of the late Dr. David J. Hyman (DJH) (1955-2020).
This work was supported by the National Institutes of Health, National Institute of Diabetes and Digestive and Kidney Diseases (DK110341 and DK129474; Vaughan, PI). Additional support was provided by the Center for Innovations in Quality, Effectiveness, and Safety at the Michael E. DeBakey VA Medical Center, Houston, TX (CIN 13-413; Naik, Virani), World Heart Federation (Virani), and the Tahir and Jooma Family (Virani).

Contributorship: $E V, J F, D J H, C J, E J$, and the CHWs conceived the presented idea. $E V, D J H$, and EJ carried out the experiment. EV, EJ, and $A A$ wrote the manuscript with support and theoretical formalism from $C J, A N, S V, A B, C B$, and $J F$. AA performed the analytic calculations.

Corresponding Author: Elizabeth M. Vaughan, DO, MPH; Division of General Internal Medicine, Baylor, Houston, TX, USA (e-mail: elizabeth.vaughan@bcm.edu).

\section{Declarations:}

Ethics Approval: The Institutional Review Board of Baylor College of Medicine approved the study.

Conflict of Interest: The authors declare that they do not have a conflict of interest.

\section{REFERENCES}

1. Centers For Disease Control, Us Department Of Health And Human Services. National Diabetes Statistics Report 2020. Atlanta, Ga: Center For Disease Control; 2020.

2. American Diabetes Association. Economic Costs of Diabetes In The U.S. In 2017. Diabetes Care. May 2018;41(5):917-928.

3. Syed ST, Gerber BS, Sharp LK. Traveling Towards Disease: Transportation Barriers To Health Care Access. I Community Health. Oct 2013;38(5):976-993.

4. Mcbrien KA, Naugler C, Ivers N, et al. Barriers To Care In Patients With Diabetes And Poor Glycemic Control-A Cross-Sectional Survey. Plos One. 2017;12(5):E0176135.

5. Peek ME, Cargill AK, Huang ES. Diabetes Health Disparities. Med Care Res Rev. 2007;64(5):101 s-156 s.

6. Marcolino MS, Oliveira JAQ, D'agostino M, Ribeiro Al, Alkmim MBM, Novillo-Ortiz D. The Impact Of Mhealth Interventions: Systematic Review Of Systematic Reviews. Jmir Mhealth Uhealth. Jan 17 2018;6(1):E23.

7. Riley SB, Marshall ES. Group Visits In Diabetes Care: A Systematic Review. Diabetes Educ. 2010;36(6):936-944.

8. So CF, Chung JW. Telehealth For Diabetes Self-Management In Primary Healthcare: A Systematic Review And Meta-Analysis. J Telemed Telecare. Jun 2018;24(5):356-364.

9. Vaughan EM, Hyman DJ, Naik AD, Samson SL, Razjouyan J, Foreyt JP. A Telehealth-Supported, Integrated Care With Chws, And MedicationAccess(Time) Program For Diabetes Improves Hbalc: A Randomized Clinical Trial. J Of Gen Intern Med. 2021;36(2):455-463.

10. Vaughan EM, Johnston CA, Moreno JP, Cardenas VC, Foreyt JP. Integrating Chws As Part Of The Team Leading Diabetes Group Visits: A Randomized Controlled Feasibility Study. Diabetes Educ. 2017;43(6).

11. Vaughan EM, Naik AD, Lewis CM, Foreyt JP, Samson SL, Hyman DJ. Telemedicine Training And Support For Community Health Workers: Improving Knowledge Of Diabetes. Telemed $J$ E Health. Feb 2020;26(2):244-250.

12. Li Z, Snieder H, Su S, Harshfield GA, Treiber FA, Wang X. A Longitudinal Study Of Blood Pressure Variability In African-American And European American Youth. J Hypertens. Apr 2010;28(4):715-722.

13. Lind M, Pivodic A, Cea-Soriano L, Nerman O, Pehrsson NG, GarciaRodriguez LA. Changes In Hbalc And Frequency Of Measuring Hbalc And Adjusting Glucose-Lowering Medications In The 10 Years Following Diagnosis Of Type 2 Diabetes: A Population-Based Study In The Uk. Diabetologia. Aug 2014;57(8):1586-1594.

14. Pani LN, Korenda L, Meigs JB, et al. Effect Of Aging On Alc Levels In Individuals Without Diabetes: Evidence From The Framingham Offspring Study And The National Health And Nutrition Examination Survey 20012004. Diabetes Care. Oct 2008;31(10):1991-1996.

15. Yu ES, Hong $\mathbf{K}$, Chun BC. A Longitudinal Analysis Of The Progression From Normal Blood Pressure To Stage 2 Hypertension: A 12-Year Korean Cohort. Bmc Public Health. Jan 6 2021;21(1):61. 
16. Radin MS. Pitfalls In Hemoglobin Alc Measurement: When Results May Be Misleading. J Gen Intern Med. Feb 2014;29(2):388-394.

17. Zoom. Zoom For Healthcare. 2021; https://Zoom.Us/Healthcare. Accessed June 2, 2021.

18. Ohmd. The Modern Healthcare Communication Platform. 2021; https:// www.Ohmd.Com. Accessed June 2, 2021

19. Critchley JA, Carey IM, Harris T, Dewilde S, Cook DG. Variability In Glycated Hemoglobin And Risk Of Poor Outcomes Among People With Type 2 Diabetes In A Large Primary Care Cohort Study. Diabetes Care. Dec 2019;42(12):2237-2246.

20. American Diabetes Association. Standards Of Medical Care In Diabetes 2021. Diabetes Care. 2021;42(Supplement 1):S1-S193.

21. Nathan DM, Kuenen J, Borg $\mathbf{R}$, et al. Translating The Alc Assay Into Estimated Average Glucose Values. Diabetes Care. Aug 2008;31(8): 14731478.

22. Little RR, Rohlfing Cl, Wiedmeyer HM, et al. The National Glycohemoglobin Standardization Program: A Five-Year Progress Report. Clin Chem. Nov 2001;47(11):1985-1992.

23. Trento M, Passera P, Borgo E, et al. A 5-Year Randomized Controlled Study Of Learning, Problem Solving Ability, And Quality Of Life Modifications In People With Type 2 Diabetes Managed By Group Care. Diabetes Care. Mar 2004;27(3):670-675.

24. Karatas S, Yesim T, Beysel S. Impact Of Lockdown Covid-19 On Metabolic Control In Type 2 Diabetes Mellitus And Healthy People. Prim Care Diabetes. Jun 2021;15(3):424-427.

25. Rothschild SK, Martin MA, Swider SM, et al. Mexican American Trial Of Community Health Workers: A Randomized Controlled Trial Of A Community Health Worker Intervention For Mexican Americans With
Type 2 Diabetes Mellitus. Am J Public Health. Aug 2014;104(8):15401548.

26. Perez-Escamilla R, Damio G, Chhabra J, et al. Impact Of A Community Health Workers-Led Structured Program On Blood Glucose Control Among Latinos With Type 2 Diabetes: The Dialbest Trial. Diabetes Care. Feb 2015;38(2):197-205.

27. Myerson R, Lu T, Tonnu-Mihara I, Huang ES. Medicaid Eligibility Expansions May Address Gaps In Access To Diabetes Medications. Health Aff (Millwood). Aug 2018;37(8):1200-1207.

28. Berkowitz SA, Karter AJ, Lyles CR, et al. Low Socioeconomic Status Is Associated With Increased Risk For Hypoglycemia In Diabetes Patients: The Diabetes Study Of Northern California (Distance). J Health Care Poor Underserved. May 2014;25(2):478-490.

29. Gucciardi E, Vahabi M, Norris N, Del Monte JP, Farnum C. The Intersection Between Food Insecurity And Diabetes: A Review. Curr Nutr Rep. 2014;3(4):324-332.

30. Zhang $\mathbf{X}$, Bullard $\mathbf{K M}$, Gregg $\mathbf{E W}$, et al. Access to Health Care and Control of Abcs of Diabetes. Diabetes Care. Jul 2012;35(7):1566-1571.

31. Bhutani S, Vandellen Mr, Cooper JA. Longitudinal Weight Gain And Related Risk Behaviors During The Covid-19 Pandemic In Adults In The Us. Nutrients. Feb 19 2021;13(2).

32. Nicholson LM, Schwirian PM, Klein EG, et al. Recruitment And Retention Strategies In Longitudinal Clinical Studies With Low-Income Populations. Contemp Clin Trials. May 2011;32(3):353-362.

Publisher's Note: Springer Nature remains neutral with regard to jurisdictional claims in published maps and institutional affiliations. 